Review Article

\title{
ENTEROCOCCUS FAECALIS CAN SURVIVE EXTREME CHALLENGES - OVERVIEW
}

\author{
Rahul Halkai', Mithra N. Hegde ${ }^{2}$, Kiran Halkai', \\ ${ }^{1}$ Ph.D. Student, ${ }^{2}$ Senior Professor \& Head of the Department, Department of Conservative and Endodontics, A.B. \\ Shetty M emorial Institute of Dental Science, Nitte University, Mangalore - 575018. \\ ${ }^{3} \mathrm{Sr}$. Lecture, Department of Conservative and Endodontics \\ Sn Hke'S Dental College, Gulbarga. \\ Correspondence: \\ Rahul Halkai \\ Ph.D. Student, Department of Conservative and Endodontics, A.B. Shetty Memorial Institute of Dental Science, \\ Nitte University, Mangalore - 575018.
}

\begin{abstract}
:
Enterococcus faecalis is a micro-organism that can survive extreme challenges. Its pathogenicity ranges from life-threatening diseases in compromised individuals to less severe conditions, systemic diseases such as endocarditis, brain abscesses, and septicaemia to infection of obturated root canals with chronic apical periodontitis. This article highlights some of the virulence factors of $E$. faecalis that may be related to endodontic infections and the periradicular inflammatory response. The most-cited virulence factors are aggregation substance, surface adhesins, sex pheromones, lipoteichoic acid, extracellular superoxide production, the lytic enzymes gelatinase and hyaluronidase, and the toxin cytolysin. Each of them may be associated with various stages of an endodontic infection as well as with periapical inflammation. While some products of the bacterium may be directly linked to damage of the periradicular tissues, a large part of the tissue damage is probably mediated by the host response to the bacterium and its products.
\end{abstract}

Keywords: Resistance enterococcusfaecalis, persisting infection.

\section{Overview :}

The most common pathway for microorganisms from the normal oral flora to the dental pulp is through an open cavity caused by dental caries in the crown of the tooth. Because of inadequate collateral circulation, a necrotic pulp is insulated from the usual cleaning processes and immune mechanisms of the body and thus cannot heal. The root canal system becomes a privileged sanctuary for microorganism, their by products, degradation products of both the microorganisms and the pulp tissue ${ }^{1}$.

Enterococci inhabit the gastrointestinal tract, the oral cavity, and the vagina in humans as normal commensals.

\begin{tabular}{|c|}
\hline Access this article online \\
\hline Quick Response Code \\
\hline
\end{tabular}

They can cause a wide variety of diseases in humans, infecting the urinary tract, b l o o d st re a m, endocardium, abdomen, biliary tract, burn wounds, and indwelling foreign devices $^{2}$. Enterococci have also been implicated in endodontic infections. Although they make up only a small proportion of the initial flora of untreated teeth with necrotic pulps ${ }^{3}$, enterococci, particularly E. faecalis, have been frequently found in obturated root canals exhibiting signs of chronic apical periodontitis, isolated in $23-70 \%$ of the positive cultures ${ }^{4 \cdot 9}$ and often occur in monoculture ${ }^{7-10 .}$. Moreover, E. faecalis was among a group of bacteria cultured from periapical lesions refractory to endodontic treatment ${ }^{11}$.

Enterococci can withstand harsh environmental conditions. As originally defined by Sherman (1937), enterococci can grow at $10^{\circ} \mathrm{C}$ and $45^{\circ} \mathrm{C}$, at pH 9.6, in $6.5 \%$ $\mathrm{NaCl}$ broth, and survive at $60^{\circ} \mathrm{C}$ for 30 minutes. E. faecalis can adapt to adverse conditions: Following pre-exposure to sublethal stress conditions, E. faecalis becomes less sensitive to normally lethal levels of sodium dodecyl sulfate, bile salts, hyperosmolarity, heat, ethanol, hydrogen peroxide, acidity, and alkalinity; furthermore, 'cross-protection' is pronounced against diverse 
challenges ${ }^{12-15}$. Starving E. faecalis cells maintain their viability for extended periods and become resistant to UV irradiation, heat, sodium hypochlorite, hydrogen peroxide, ethanol, and acid ${ }^{16,17}$. E. faecalis, moreover, can enter the viable but non-cultivable (VBNC) state, a survival mechanism adopted by a group of bacteria when exposed to environmental stress, and resuscitate upon returning to favorable conditions ${ }^{18}$. The ability of $\mathrm{E}$. faecalis to tolerate or adapt to harsh environmental conditions may act as an advantage over other species. It may explain its survival in root canal infections, where nutrients are scarce and there are limited means of escape from root canal medicaments.

Enterococcus faecalis is a predominant organism that plays a major role in the etology of persistent lesions after root canal treatment ${ }^{19,20}$. Studies investigating its occurrence in root filled teeth with periradicular antimicrobial resistance and the ability to adapt to changing environment help $\mathrm{E}$ faecalis to persist in root canal. E faecalis can adhere to root canal walls, accumulate, and form communities organized in bio film, which helps it resist destruction by enabling the bacteria to become 1,000 times more resistant to phagocytosis, antibodies, and antimicrobials than non- bio film-producing organisms ${ }^{21}$. Current concepts suggest that persisting infections subsequent to endodontic therapy are caused by one or two bacterial species that are "too robust" to be eliminated by conventional treatment measures. As a consequence, numerous studies are exploring the characteristics of these "most" resistant organisms to define an effective treatment strategy to eradicate them from root canals. By taking an ecological perspective, the nature of persisting endodontic infections depends not on the robustness of the organisms in the infected site, but on their capability of adapting their physiology to the new environmental conditions set by the treatment. Changes in the environment, such as an increase in $\mathrm{pH}$ by calcium hydroxide or the effect of antimicrobials, are capable of triggering genetic cascades that modify the physiological characteristics of bacterial cells. Surface adherence by bacteria to form biofilms is a good example of bacterial adaptation and one that is pertinent to endodonticinfections.
Upon contamination of the root canal with the bacterium, it can colonize the dentinal walls, adhering to the mineral part, probably through Lipoteichoic acids (LTA), and to the collagen through Aggregation substance (AS) and other surface adhesins. These surface adhesins 'Ace', which is expressed by the bacterium under disease conditions and particularly under stress ${ }^{22}$. Bacteria face a variety of stressful conditions in the root canal, such as nutrient deficiency, toxins of other bacteria, and endodontic medicaments. These conditions may modulate the adhesin expression of the bacterium. In addition, leakage of serum into the root canal can induce the expression of Aggregation substance (AS) and other carbohydrate moieties, thereby increasing the adhesiveness of the bacterium. Adhesion to dentin and penetration along dentinal tubules by $E$. faecalis may serve as a means of protection from endodontic medicaments. An example is calcium hydroxide. When calcium hydroxide is placed in the root canal, the $\mathrm{pH}$ decreases sharply toward deeper dentinal zones ${ }^{23,24}$. Thus, bacteria that have penetrated more deeply into the dentinal tubules and established footholds peripheral to the main root canal are at an advantage. Another mechanism by which E. faecalis survives may be through Lipoteichoic acids (LTA), which has been associated with resistance of the bacterium against a variety of lethal conditions ${ }^{25}$.

Since $E$. faecalis suppresses the growth of other bacteria with its cytolysin, AS-48 (Aggregation substance), and other bacteriocins, Among the target cells of cytolysin are the erythrocytes ${ }^{26-27}$, PM Ns and macrophages ${ }^{27}$, and a broad range of Gram-positive, but not Gram-negative, organisms ${ }^{28,29}$. It has been hypothesized that if the bacteriocin effect of cytolysin of $E$. faecalis favors colonization of the Gram-negatives, there could be a shift to a bacterial flora usually associated with periodontal disease $^{29}$. The latter factors are not believed to be pathogenic in humans. However, along with cytolysin, they facilitate the dominance of $\mathrm{E}$. faecalis in a mixed infection and serve as means to obtain ecological advantages which can result in disease in man. 
The root canal is hardly a nutrient-rich medium, but $\mathrm{E}$. faecalis may derive the energy it needs from the hyaluronan present in the dentin through degradation by hyaluronidase. E. faecalis may also feed on serum components present in the fluid in the dentinal tubules. Moreover, an inadequate apical seal of root fillings may allow serum to flow into the root canal. Therefore, it seems that, even in a well-debrided and coronally well-sealed root canal, remaining or arriving cells of $E$. faecalis may still grow and utilize local sources of energy and nutrients.

Production of extracellular superoxide and release of the lytic enzymes gelatinase and hyaluronidase and the toxin cytolysin by $\mathrm{E}$. faecalis can cause direct damage in the dentinal as well as in the periapical tissues. In contrast, E. faecalis can also induce host-mediated tissue damage in the periradicular tissues. Since cells of E. faecalis in the dentinal tubules cannot be reached and eliminated by the cells of the host defense system, they may elicit a permanent provocative effect on these cells. PMN leukocytes, lymphocytes, monocytes, and macrophages are stimulated by a group of virulence factors of $E$. faecalis, which will contribute to the periradicular damage.

It has been proposed that, since strains of $E$. faecalis frequently harbor plasmids determining antibiotic resistance, cytolysin, and/or bacteriocin, they may represent a reservoir of genetic information available to other bacteria in the intestine ${ }^{30}$. This applies to the root canal microbiota as well. While antibiotic resistance and other virulence traits can be disseminated by means of the sex-pheromone-responsive plasmid transfer among the strains of $\mathrm{E}$. faecalis, gene transfer is also possible from $\mathrm{E}$. faecalis to bacteria of other species or even of other genera through sex-pheromone-independent conjugation. So far, there is no information on whether multiple strains of $E$. faecalis simultaneously participate in endodontic infections in utilizing the sex-pheromone-related gene transfer. However, E. faecalis frequently colonizes the root canal together with bacteria of other species and/or genera, and it may use the latter pathway of gene transfer. This is associated mainly with the transfer of antibiotic resistance genes. Thus, bacteria resistant to multiple antibiotics can be generated within the root canals, where E. faecalis plays a pivotal role. It has been reported that micro-organisms from the root canal can be seeded into the bloodstream during endodontic treatment, and this has the potential to bring about serious systemic diseases such as endocarditis, brain abscesses, and septicemia, particularly for compromised patients ${ }^{31,32}$, although this may be a rare clinical occurrence, there are reported cases related to endodontic infections and endodontic treatment ${ }^{33-35}$. In this context, bacteria resistant to multiple antibiotics pose particular problems. Indeed, in marginal periodontitis refractory to conventional treatment, an increased prevalence of bacteria resistant to antibiotics may be found ${ }^{36}$.

It cannot be excluded that bacteria may pass through the apical foramen to the periradicular lesion during the course of endodontic infection and elicit host responses. However, the focus of infection is the root canal and the dentinal tubules, which are inaccessible to the elements of the host defense system.

Treatment or preventive procedures should mainly include local, rather than systemic, means. In addition to disinfectants, physical removal of cells of $E$. faecalis through debridement of the root canal remains essential, since remnants containing Lipoteichoic acids (LTA) may still sustain the inflammation. The use of agents blocking the expression of virulence genes or modulating their products may find a role in future treatments of persistent endodontic infections with E. faecalis. For example, sensitization of the bacteria to root canal medicaments, which are otherwise ineffective, particularly through targeting the Lipoteichoic acids (LTA) synthesis or $d$ alanylation of the Lipoteichoic acids (LTA) chain, may be possible, but a better understanding of the regulation of the virulence genes is necessary.

Another possible preventive measure to avoid invasion of the dentinal tubules by $\mathrm{E}$. faecalis may be through disruption of the dentinal collagen, the target for the adhesins. Enzymatic modulation is one possible way of 
altering the collagen. Similarly, proteinaceous bacterial adhesins may be targeted by protein-digesting agents such as trypsin. These methods have been tested in vitro and resulted in decreased adherence of $\mathrm{E}$. faecalis to collagencoated surfaces ${ }^{37}$.

\section{Conclusion:}

This overview has dealt with the virulence factors of $E$. faecalis that enables the bacterium to establish an endodontic infection and maintain a periradicular inflammation. The pathogenesis of the periradicular lesions is definitely a very complex process that may involve a large number of host and microbial factors ${ }^{38-40}$. In the present context, only those aspects of the immune and

\section{References:}

1) Naidorf IJ(1972). Inflammation and infection of pulp and periapical tissues. Oral surg ery34,486-96.

2) Jett BD, Huycke M M , Gilmore MS (1994). Virulence of enterococci. Clin Microbiol Rev 7,462-78.

3) Sundqvist G (1992). Associations between microbial species in dental root canal infections. Oral Microbiology and Immunology 7,257-62.

4) Engström B (1964). The significance of enterococci in root canal treatment. Odontology Review 15,87-106.

5) Möller ÅJ (1966). Microbiological examination of root canals and periapical tissues of human teeth. Odontologisk tidskrift 74,1-380.

6) Molander A, Reit C, Dahlén G, Kvist T (1998). Microbiological status of rootfilled teeth with apical periodontitis. International Endodontic Journal 31,1-7.

7) Sundqvist G, Figdor D, Persson S, Sjögren U (1998). Microbiologic analysis of teeth with failed endodontic treatment and the outcome of conservative re-treatment. Oral Surgery Oral M edicine Oral Pathology 85,86-93.

8) Peciuliene V, Balciuniene I, Eriksen HM, Haapasalo M (2000). Isolation of Enterococcus faecalis in previously root-filled canals in a Lithuanian population. Journal of Endodontics 26,593-95.

9) Hancock HH, Sigurdsson A, Trope M, M oiseiwitsch J (2001). Bacteria isolated after unsuccessful endodontic treatment in a North American population. Oral Surgery Oral M edicine Oral Pathology 91,579-86.

10) Dahlén G, Samuelsson W, M olander A, Reit C (2000). Identification and antimicrobial susceptibility of enterococci isolated from the root canal. Oral M icrobiology Immunology 15,309-12.

11) Sunde PT, Olsen I, Debelian GJ, Tronstad L (2002). Microbiota of periapical lesions refractory to endodontic therapy. Journal of Endodontics 28,304-10.

12) Flahaut S, Hartke A, Giard JC, Benachour A, Boutibonnes P, Auffray $Y$ (1996a). Relationship between stress response towards bile salts, acid and heat treatment in Enterococcus faecalis. Federation of European Microbiological Societies M icrobiology Letters 138,49-54.

13) Flahaut S, Frere J, Boutibonnes P, Auffray Y (1996b). Comparison of the bile salts and sodium dodecyl sulfate stress responses in Enterococcus faecalis. Applied Environmental M icrobiology 62, 2416-20.

14) Flahaut S, Benachour A, Giard JC, Boutibonnes P, Auffray Y (1996c). Defense against lethal treatments and de novo protein synthesis induced by $\mathrm{NaCl}$ in Enterococcus faecalis ATCC 19433. Archives of Microbiology 165,317-24.

15) Flahaut S, Hartke A, Giard JC, Auffray Y (1997). Alkaline stress response in Enterococcus faecalis: adaptation, cross protection, and changes in protein synthesis. Applied Environmental M icrobiology 63,812-14.

16) Giard JC, Hartke A, Flahaut S, Benachour A, Boutibonnes $P$, Auffray $Y$ (1996). Starvation-induced multiresistance in Enterococcus faecalis inflammatory events likely to occur within the periradicular lesion in relation to the virulence factors of $\mathrm{E}$. faecalis have been discussed. It has been established that the primary periradicular lesion is a consequence of a mixed microbial flora rather than solely of E. faecalis. However, in apical periodontitis that persists despite root canal treatment, $\mathrm{E}$. faecalis is frequently the dominant, sometimes the only, pathogen, suggesting that this species alone has the potential to maintain root canal infection and periradicular lesion. A better understanding of the role of the virulence factors of $\mathrm{E}$. faecalis in endodontic infections may help in the development of new strategies to prevent or to eliminate the infection by this species, thereby improving treatment resultsin endodontics.

JH2-2. Current Microbiology 32,264-71.

17) Hartke A, Giard JC, Laplace JM, Auffray Y (1998). Survival of Enterococcus faecalis in an oligotrophic microcosm: changes in morphology, development of general stress resistance, and analysis of protein synthesis. Applied Environmental M icrobiology 64,4238-45.

18) Lleò MM, Bonato $B$, Tafi MC, Signoretto $C$, Boaretti M, Canepari $P$ (2001). Resuscitation rate in different enterococcal species in the viable but non-culturable state. Journal of Applied Microbiology 91,1095-102.

19) Ro^ c as IN, Jung IY, Lee $C Y$, et al (2004). Polymerase chain reaction identification of microorganisms in previously root-filled teeth in a South Korean population. Journal of Endodontics 30,504-8.

20) Pinheiro ET \& Gomes BP et al (2003) Pinheiro ET, Gomes BP, Ferraz CC, et al. (2003). Microorganisms from canals of root-filled teeth with periapical lesions. International Endodontic Journal 36,1-11.

21) Stuart CH, Schwartz SA, Beeson TJ, et al. (2006): its role in root canal treatment failure and current concepts in retreatment. Journal of Endodontics 32,93-8.

22) Rich RL, Kreikemeyer B, Owens RT, LaBrenz S, Narayana SV, Weinstock $\mathrm{GM}$, et al. (1999). Ace is a collagen-binding MSCRAMM from Enterococcus faecalis. Journal of microbial Chemistry 274,26939-45.

23) Tronstad L, Andreasen JO, Hasselgren G, Kristerson L, Riis I (1981). pH changes in dental tissues after root canal filling with calcium hydroxide. Journal of Endodontics 7,17-21.

24) Nerwich A, Figdor D, M esser HH (1993). pH changes in root dentin over a 4-week period following root canal dressing with calcium hydroxide. Journal of Endodontics 19,302-6.

25) Shungu DL, Cornett JB, Shockman GD (1979). Morphological and physiological study of autolytic-defective Streptococcus faecium strains. Journal of Bacteriology 138,598-608.

26) Basinger SF, Jackson RW (1968). Bacteriocin (hemolysin) of Streptococcus zymogenes. Journal of Bacteriology 96, 1895-902.

27) M iyazaki S, Ohno A, Kobayashi I, Uji T, Yamaguchi K, Goto S (1993). Cytotoxic effect of hemolytic culture supernatant from Enterococcus faecalis on mouse polymorphonuclear neutrophils and macrophages. Microbiology and Immunology 37,265-70.

28) Jackson RW (1971).Bacteriolysis and inhibition of Gram-positive bacteria by components of Streptococcus zymogenes lysine. Journal of Bacteriology 105,156-9.

29) Jett BD, Gilmore MS (1990). The growth-inhibitory effect of the Enterococcus faecalis bacteriocin encoded by PAD1 extends to the oral streptococci. J ournal of Dental Research 69,1640-5. 
30) Clewell DB, Weaver KE (1989). Sex pheromones and plasmid transfer in Enterococcusfaecalis. Plasmid 21,175- 84.

31) Debelian GJ, Olsen I, Tronstad L (1994). Systemic diseases caused by oral microorganisms. Endodontic Dental Traumatology 10, 57-65.

32) Debelian GJ, Olsen I, Tronstad L (1995). Bacteremia in conjunction with endodontic therapy. Endodontic Dental Traumatology 11,142-9.

33) Henig EF, Derschowitz T, Shalit M, Toledo E, Tikva P, Aviv T (1978). Brain abcess following dental infection. Oral Surgery Oral Medicine Oral Pathology 45,955-8.

34) Lee GT (1984). Septicaemia as a complication of endodontic treatment. Journal of Dentistry 12,241-42.

35) Green JG, Haisch L (1988). Infective endocarditis and antibiotic prophylaxis failure following an endodontic procedure. General Dentistry 36,131-3.

36) Handal T, Caugant DA, Olsen I (2003). Antibiotic resistance in bacteria isolated from subgingival plaque in a Norwegian population with refractory marginal periodontitis. Antimicrobial Agents and Chemotherapy 47, 1443-46

37) Xiao J, Höök M , Weinstock GM , M urray BE (1998). Conditional adherence of Enterococcus faecalis to extracellular matrix proteins. Federation of European M icrobiological Societies immunology and medical microbiology21,287-95.

38) Torabinejad M, Eby WC, Naidorf IJ (1985). Inflammatory and immunological aspects of the pathogenesis of human periapical lesions. Journal of Endodontic 11,479-88.

39)Stashenko $P$ (1998). Etiology and pathogenesis of pulpitis and apical periodontitis. In: Essential endodontology. Ørstavik D, Pitt Ford TR, editors. Wiltshire: Blackwell Science, pp. 42-67.

40) Takahashi K (1998). Microbiological, pathological, inflammatory, immunological and molecular biological aspects of periradicular disease. International Endodontic Journal 31,311-25. 